\title{
PENGARUH RELATIONHIP MARKETINGTERHADAP LOYALITAS PELANGGAN LYLY BAKERY LAMONGAN
}

\author{
*(Mohammad Yaskun ${ }^{1}$, Diah Ayu Novitasari ${ }^{2}$ \\ Prodi Manajemen, Fakultas Ekonomi, Universitas Islam Lamongan \\ Jl. Veteran No.53A Lamongan \\ Telp. ( 0322 ) 324706, Faks. ( 0322 ) 324706 \\ Email:jpim.unisla@gmail.com
}

\begin{abstract}
ABSTRAK
Penelitian ini bertujuan untuk mengetahui ada tidaknya pengaruh relationhip marketingterhadap loyalitas pelanggan Lyly Bakery Lamongan. Populasi dalam penelitian ini adalah para pelanggan Lyly Bakery dengan jumlah sampel 100 responden yang diperoleh dengan menggunakan teknik purposive sampling, pengumpulan data dilakukan melalui metode kuesioner dan dianalisi dengan menggunakan teknik analisis regresi berganda. Hasil dari penelitian ini diketahui bahwa variabel relationhip marketingsecara simultan berpengaruh signifikan terhadap loyalitas pelanggan. Dimensi relationship marketing secara simultan berpengaruh signifikan terhadap loyalitas pelanggan, artinya dimensi relationship marketingini akan meningkatkan loyalitas pelanggan terhadap Lyly Bakery Lamongan.
\end{abstract}

Kata Kunci: Relationship Marketing, Loyalitas Pelanggan.

\section{PENDAHULUAN}

Para pelaku bisnis dibidang penjualan roti bakery harus tanggap terhadap perubahan yang saat ini terjadi begitu cepat di dalam dunia bisnis. Perusahaan dituntut untuk dapat menyesuaikan diri dengan perubahan-perubahan yang terjadi, sebab jika sampai gagal eksistensi perusahaan akan terancam, dan perusahaan tidak akan mampu untuk bertahan didalam persaingan bisnis.Dalam menghadapi hal ini, banyak perusahaan bersaing untuk dapat meningkatkan pangsa pasarnya, sehingga menjadi motivasi bagiperusahaan untuk bekerja keras dalam memperbaiki bisnisnya. Strategi yang bisa dilakukan oleh prusahaan yaitu dengan menciptakan serta membangun loyalitas pelanggan.Loyalitas pelanggan mutlak diperlukan oleh sebuah perusahaan untuk dapat tetap survive dan mampu bersaing dengan perusahaan lain. Untuk membangun loyalitas konsumen diperlukan adanya usaha-usaha dari perusahaan untuk tetap memberikan kualitas terbaik dalam setiap produk atau jasa yang di milikinya, sehingga terbentuk persepsi kualitas yang kuat di benak konsumen. Mempertahankan semua pelanggan yang ada umumnya akan lebih menguntungkan dibandingkan dengan pergantian pelanggan karena biaya untuk menarik pelanggan baru bisa lima kali lipat dari biaya mempertahankan seorang pelanggan yang sudah ada. Kotler, dalam Sutopo (2011:4).Loyalitas adalah hasil dari menjalin hubungan baik dalam jangka panjang dengan pelanggan. Menjalankan sebuah usaha bisnis diperlukan pen-dekatan yang berbasis hubungan, agar diperoleh pemahaman tentang apa yang dibutuhkan dan diinginkan pelanggan serta memandang pelanggan sebagai aset jangka panjang. Barnes dalam Samuel (2012:33).Loyalitas menggambarkan suatu komitmen pelanggan untuk melakukan bisnis dengan organisasi, dengan membeli barang dan jasa secara berulang, dan merekomendasikan jasa dan produknya kepada teman dan kelompoknya. Para pemasar menyadari bahwa loyalitas 
pelanggan merupakan dorongan yang sangat penting untuk menciptakan penjualan. Menurut pelanggan, perusahaan yang berkinerja baik adalah pelanggan yang bersedia melakukan pembelian pertama dan kemudian berkeinginan untuk melakukan pembelian berikutnya berulangulang, Chan, dalam Samuel (2012:34).Relationship

marketingmemaparkan bahwa loyalitas pelanggan harus dibangun dengan usaha keras dalam bentuk personalisasi dimana pelanggan menjadi inti dari aktivitas pemasaran. Pelanggan yang memiliki maksud untuk membeli kembali dan merekomendasikan produk dan jasa kepada orang lain kemungkinan besar sebagai pelanggan yang loyal. Dengan meningkatkan kelangsungan hubungan dengan pelanggan lama dan terus mengakuisisi dengan pelanggan baru dengan konsep loyalitas pelanggan, kita akan mempunyai pengaruh yang lebih besar dari bagian pasar, karena strategi bisnis difokuskan pada kelanggengan dan pemuasan dari setiap palanggannya dengan penggunaan strategi relationship marketing.Sehingga dengan adanya strategi relationship marketing berupaya untuk memperpanjang umur waktu hidup pelanggan sebagai individu yang bertransaksi dan dapat menjaga loyalitas pelanggan, Samuel (2012:34).Winer dalam Murti (2013:7) berpendapat jika perusahaan dapat mengkombinasikan kemampuan untuk merespon dan menyediakan permintaan pelanggan dengan baik, serta melakukan hubungan yang lebih intensif dengan pelanggan melalui peningkatan kualitas layanan pelanggan sesuai dengan permintaan pelanggan maka perusahaan tersebut dapat mempertahankan pelanggannya untuk jangka panjang. Loyalitas pelanggan terhadap suatu produk dan jasa berkaitandengan konsep relationship marketing dilandasi oleh faktor-faktor tertentu. Sorce dalam Murti (2013) menyebutkan beberapa faktor yang menentukan relationship marketing, diantaranya commitment, trust, power, control, balance of power, interdependence,

communication, cooperation, idiosyncrat ic investments, dan conflict resolution. Terdapat beberapa faktor yang dapat mempengaruhi loyalitas pelanggan toko roti Lyly Bakery Lamongan,diantaranya adalah trust, commitment, communication, dan complaint handling.

\section{METODE PENELITIAN}

Pendekatan yang digunakan dalam penelitian ini adalah pendekatan metode penelitian kuantitatif.Populasi dalam penelitian ini adalah pelanggan toko roti Lyly Bakery Lamongan pada periode tahun 2016 yaitu berjumlah 1.676 pelanggan.Teknik pengambilan sampel yang digunakan dalam penelitian adalah purposive sampling.Besarnya ukuran sampel yang akan diteliti dari suatu populasi dapat digunakan rumus pendekatan Slovin (Umar, 2009:146) sebagai berikut:

Keterangan:

$$
n=\frac{N}{1+N e^{2}}
$$

$$
\begin{aligned}
& \mathrm{n}=\text { Ukuran Sampel } \\
& \mathrm{N}=\text { Ukuran Populasi } \\
& \mathrm{e}=10 \% \text { (prosentase tingkat }
\end{aligned}
$$

kesalahan pengambilan sampel).

Berdasarkan rumus pendekatan Slovindiatas, maka yang menjadi sampel dalam penelitian ini sebanyak :

$$
\begin{aligned}
& \mathrm{n}=\frac{}{1+676} \begin{array}{c}
1.676(0.1)^{2} \\
\mathrm{n}=\frac{1.676}{1+16,76} \\
1.676
\end{array}
\end{aligned}
$$




$$
\begin{aligned}
& \mathrm{n}=\frac{}{17,76} \\
& n=94,36=100 \text { responden }
\end{aligned}
$$

Jadi, sampel yang digunakan dalam penelitian ini sebanyak 100 pelanggan.

Metode pengumpulan data yang dilakukan dalam penelitian adalah; kuisioner, wawancara, observasi, dan studi pustaka. Alat analisis data menggunakan program SPSS 19 (Statistical Package for Social Science 19).

\section{HASIL DAN PEMBAHASAN Uji Validitas}

Dari hasil uji validitas untuk butir pertanyaan semua variabel diperoleh nilai koefisien yang terdapat pada tabel dengan menggunakan jumlah responden sebanyak 100, maka nilai r-tabel diperoleh melalui $\mathrm{df}=\mathrm{n}-\mathrm{k}-1$. Jadi $\mathrm{df}$ $=100-4-1=95$, maka $\mathrm{r}$-tabel senilai 0,202 . Valid tidaknya suatu instrumen dapat dilihat dengan membandingkan nilai Corrected Item Total Corelation (r-hitung) dengan r-tabel, apabila rhitung > r-tabel $(0,202)$ maka instrumen pertanyaan dianggap valid. Hasil perhitungan uji validitas wariabel kepercayaan $\left(\mathrm{X}_{1}\right)$, komitmen $\left(\mathrm{X}_{2}\right)$, komunikasi $\left(\mathrm{X}_{3}\right)$, penanganan keluhan $\left(\mathrm{X}_{4}\right)$, dan loyalitas pelanggan (Y) dianggap valid karena seluruh butir pertanyaan memiliki nilai r-hitung > dari r-tabel.

\section{Uji Reliabilitas}

Uji realibilitas menggunakan teknik Cronbach Alpha. Realibilitas suatu konstruk variabel dikatakan baik jika memiliki nilai Cronbach Alpha > 0,600. Dan hasil uji reliabilitas menunjukkan bahwa semua variabel $\left(\mathrm{X}_{1}\right),\left(\mathrm{X}_{2}\right),\left(\mathrm{X}_{3}\right)$, $\left(\mathrm{X}_{4}\right)$, dan $(\mathrm{Y})$ mempunyai r-hitung $>$ rminimum. Sehingga dapat dikatakan bahwa instrumen penelitian dalam variabel dan terikat pada kuisioner adalah reliabel.

\section{Uji Asumsi Klasik}

a. Multikolinieritas

Suatu variabel menunjukkan gejala multikolinieritas bisa dilihat dari nilaiVIF (Variance Inflation Factor) yang tinggi pada variabel-variabel bebas suatu model regresi. Nilai VIF yang lebih besar dari 10 menunjukkan adanya gejala multikolinieritas dalam model regresi. Berdasarkan tabel nilai variabel menunjukkan bahwa masing" variabel yang digunakan sebagai prediktor model regresi menunjukkan nilai VIF yang cukup kecil, dimana semuanya berada di bawah 10 dan nilai tolerance lebih dari 0,1. Hal ini berarti bahwa variabel-variabel bebas yang digunakan dalam penelitian tidak menunjukkan adanya gejala multikolinieritas.

a. Heteroskedastisitas

Pengujian heteroskedastisitas dilakukan dengan menggunakan Scatter Plot. Hasil pengujian heteroskedastisitas menunjukkan tidak terdapat pola yang jelas dari titik - titik tersebut. Hal ini menunjukkan bahwa model regresi tidak memiliki gejala adanya heteroskedastisitas, yang berarti bahwa tidak ada gangguan yang berarti dalam model regresi ini..

b. Autokorelasi

Deteksi adanya problem autokorelasi dengan menggunakan Durbin Watson dimana :

- Angka Durbin Watson dibawah -2 berarti ada autokorelasi positif.

- Angka Durbin Watson diatas -2 sampai +2 berarti tidak ada autokorelasi .

- Angka Durbin Watson diatas +2 berarti ada autokorelasi negatif.

Pada output model summary terdapat nilai Durbin Watson 
sebesar 1,820. Nilai tersebut dapat dinyatakan berada diatas nilai -2 sampai +2 . Dengan demikian dapat disimpulkan bahwa tidak terjadi autokolerasi antara data pengamatan.

c. Normalitas

Hasil pengujian menunjukkan bahwa titik - titik berada tidak jauh dari garis diagonal, berarti model regresi sudah berdistribusi normal.

\section{Korelasi Berganda}

Korelasi berganda merupakan alat ukur mengenai hubungan yang terjadi antara variabel terikat (Y) dan variabel bebas (X). Korelasi berganda berarti pula indeks atau angka yang digunakan untuk mengukur keeratan hubungan antara 2 variabel atau lebih. Dari hasil perhitungan SPSS diketahui bahwa besarnya hubungan antara variabel kepercayaan $\left(\mathrm{X}_{1}\right)$, komitmen $\left(\mathrm{X}_{2}\right)$, komunikasi $\left(\mathrm{X}_{3}\right)$, dan penanganan keluhan $\left(\mathrm{X}_{4}\right)$ terhadap loyalitas pelanggan mempunyai hubungan korelasi yang kuat dan searah. Hal tersebut ditunjukkan dengan hasil korelasi berganda $\mathrm{R}$ yang diperoleh adalah sebesar 0,737 artinya terdapat korelasi yang sangat kuat dan dengan hubungan yang searah (positif).

3. Koefisien Determinasi

Koefisien determinasi $\mathrm{R}^{2}$ yang diperoleh adalah sebesar 0,543 berarti bahwa variabel kepercayaan $\left(\mathrm{X}_{1}\right)$, komitmen $\left(\mathrm{X}_{2}\right)$, komunikasi $\left(\mathrm{X}_{3}\right)$, dan penanganan keluhan $\left(\mathrm{X}_{4}\right)$. mampu menjelaskan keputusan pembelian sebesar 54,3\% sedangkan sisanya 0,457 atau $45,7 \%$ dapat dijelaskan oleh variabel lain yang tidak diteliti suatu misal bauran pemasaran yang tidak dibahas dalam penelitian ini adalah orang, proses, dan lingkungan fisik yang mempengaruhi loyalitas pelanggan.

4. Analisis Regresi Linier Berganda Persamaan regresi linier berganda sebagai berikut:

$\mathrm{Y}=2,112+0,135 \mathrm{X}_{1}+0,195 \mathrm{X}_{2}+$ $0,186 X_{3}+0,144 X_{4}$

Dari model regresi yang terbentuk, maka diperoleh hubungan antara masing-masing variabel independen dengan variabel dependen dapat dijelaskan sebagai berikut :

- Nilai konstanta (a)

Bertanda positif menyatakan bahwa jika semua variabel bebas memiliki nilai nol (0) maka nilai variabel terikat sebesar 2,112 yang berarti tidak ada kegiatan dari keempat variabel bebas yang mempengaruhi keputusan pembelian.

- Kepercayaan $\left(\mathrm{X}_{1}\right)$ terhadap loyalitas pelanggan $(\mathrm{Y})$

Nilai koefisien kepercayaan untuk variabel $\mathrm{X}_{1}$ sebesar 0,135. Hal ini mengandung arti bahwa setiap kenaikan kepercayaan satu satuan maka variabel terikat (Y) akan naik sebesar 0,135 dengan asumsi bahwa variabel bebas yang lain dari model regresi adalah tetap.

- Komitmen $\left(\mathrm{X}_{2}\right)$ terhadap loyalitas pelanggan $(\mathrm{Y})$

Nilai koefisien komitmen untuk variabel $\mathrm{X}_{2}$ sebesar 0,195 . Hal ini mengandung arti bahwa setiap kenaikan komitmen satu satuan maka variabel terikat (Y) akan naik sebesar 0,195 dengan asumsi bahwa variabel bebas yang lain dari model regresi adalah tetap.

- Komunikasi $\left(\mathrm{X}_{3}\right)$ terhadap loyalitas pelanggan $(\mathrm{Y})$

Nilai koefisien komunikasi untuk variabel $\mathrm{X}_{3}$ sebesar 0,186 . Hal ini mengandung arti bahwa setiap kenaikan komunikasi satu 
satuan maka variabel terikat (Y) akan naik sebesar 0,186 dengan asumsi bahwa variabel bebas yang lain dari model regresi adalah tetap.

- Penanganan Keluhan $\left(X_{4}\right)$ terhadap loyalitas pelanggan $(\mathrm{Y})$ Nilai koefisien penanganan keluhan untuk variabel $\mathrm{X}_{4}$ sebesar 0,144. Hal ini mengandung arti bahwa setiap kenaikan penanganan keluhan satu satuan maka variabel terikat (Y) akan naik sebesar 0,144 dengan asumsi bahwa variabel bebas yang lain dari model regresi adalah tetap.

\section{Uji F}

Berdasarkan hasil uji $F$ menunjukkan bahwa secara bersama - sama variabel dari Relationship Marketing (kepercayaan $\mathrm{X}_{1}$, komitmen $\mathrm{X}_{2}$, komunikasi $X_{3}$, dan penanganan keluhan $\mathrm{X}_{4}$ ) berpengaruh signifikan terhadap loyalitas pelanggan dapat ditunjukkan dari uji $\mathrm{F}$ sebesar 28,273dan nilai $\mathrm{F}$-tabel $=2,47$, maka F-hitung $(28,273)>$ F-tabel $(2,47)$, maka $\mathrm{H}_{0}$ ditolak dan $\mathrm{H}_{\mathrm{a}}$ diterima.

6. Uji t

Bedasarkan hasil uji $t$, dan pengaruh variabel dimensi Relationship Marketing yang dominan terhadap loyalitas pelanggan.

a. Pengaruh kepercayaan Terhadap loyalitas pelanggan

Terlihat pada kolom coefficients terdapat nilai sig 0,002. Nilai sig lebih kecil dari nilai probabilitas yaitu $0,002<0,05$ maka $\mathrm{H}_{\mathrm{a}}$ diterima dan $\mathrm{H}_{0}$ ditolak. Variabel $\mathrm{X}_{1}$ mempunyai t-hitung sebesar 3,123 dan t-tabel 1,985. Jadi t-hitung > t-tabel dapat disimpulkan bahwa variabel $\mathrm{X}_{1}$ memiliki kontribusi terhadap Y.
Nilai $t$ positif menunjukkan bahwa variabel $\mathrm{X}_{1}$ mempunyai hubungan yang searah dengan Y, jadi variabel kepercayaan memiliki pengaruh signifikan terhadap loyalitas pelanggan.

b. Pengaruh komitmen Terhadap loyalitas pelanggan

Terlihat pada kolom coefficients terdapat nilai sig 0,000 . Nilai sig lebih kecil dari nilai probabilitas yaitu $0,000<0,05$ maka $\mathrm{H}_{\mathrm{a}}$ diterima dan $\mathrm{H}_{0}$ ditolak. Variabel $\mathrm{X}_{2}$ mempunyai t-hitung sebesar 5,859 dan t-tabel 1,985. Jadi t-hitung > t-tabel dapat disimpulkan bahwa variabel $\mathrm{X}_{2}$ memiliki kontribusi terhadap Y. Nilai $t$ positif menunjukkan bahwa variabel $\mathrm{X}_{2}$ mempunyai hubungan yang searah dengan Y, jadi variabel komitmen memiliki pengaruh signifikan terhadap loyalitas pelanggan.

c. Pengaruh komunikasi Terhadap loyalitas pelanggan

Terlihat pada kolom coefficients terdapat nilai sig 0,000 . Nilai sig lebih kecil dari nilai probabilitas yaitu $0,000<0,05$ maka $\mathrm{H}_{\mathrm{a}}$ diterima dan $\mathrm{H}_{0}$ ditolak. Variabel $\mathrm{X}_{3}$ mempunyai t-hitung sebesar 4,792 dan t-tabel 1,985. Jadi t-hitung > t-tabel dapat disimpulkan bahwa variabel $\mathrm{X}_{3}$ memiliki kontribusi terhadap Y. Nilai $t$ positif menunjukkan bahwa variabel $\mathrm{X}_{3}$ mempunyai hubungan yang searah dengan Y, jadi variabel komunikasi memiliki pengaruh signifikan terhadap loyalitas pelanggan.

d. Pengaruh penanganan keluhan Terhadap loyalitas pelanggan Terlihat pada kolom coefficients terdapat nilai sig 0,005 . Nilai sig lebih kecil dari nilai probabilitas yaitu $0,005<0,05$ maka $\mathrm{H}_{\mathrm{a}}$ diterima dan $\mathrm{H}_{0}$ ditolak. 
Variabel $\mathrm{X}_{4}$ mempunyai t-hitung sebesar 2,870 dan t-tabel 1,985. Jadi t-hitung > t-tabel dapat disimpulkan bahwa variabel $\mathrm{X}_{4}$ memiliki kontribusi terhadap Y. Nilai $t$ positif menunjukkan bahwa variabel $\mathrm{X}_{4}$ mempunyai hubungan yang searah dengan Y, jadi variabel penanganan keluhan memiliki pengaruh signifikan terhadap loyalitas pelanggan.

e. Hasil dari keempat dimensi relationship markrting pengujian hipotesis, dapat diketahui bahwa variabel yang berpengaruh dominan terhadap variabel terikat adalah variabel komitmen $\left(\mathrm{X}_{2}\right)$ dengan nilai $\mathrm{t}$ hitung paling besar yaitu 5,859.

\section{KESIMPULAN DAN SARAN Kesimpulan}

Berdasarkan analisis dan pembahasan yang telah dikemukakan, maka kesimpulannya sebagai berikut:

1. Variabel kepercayaan $\left(\mathrm{X}_{1}\right)$, secara parsial mempunyai pengaruh signifikan terhadap loyalitas pelanggan (Y), Nilai sig lebih kecil dari nilai probabilitas yaitu $0,002<$ 0,05 maka $\mathrm{H}_{\mathrm{a}}$ diterima dan $\mathrm{H}_{0}$ ditolak. Variabel $\mathrm{X}_{1}$ mempunyai thitung sebesar 3,123 dan t-tabel 1,985, maka t-hitung $>$ t-tabel dapat disimpulkan bahwa variabel $\mathrm{X}_{1}$ secara parsial mempunyai pengaruh signifikan terhadap loyalitas pelanggan (Y).

Variabel komitmen $\left(\mathrm{X}_{2}\right)$, secara parsial mempunyai pengaruh signifikan terhadap loyalitas pelanggan (Y), Nilai sig lebih kecil dari nilai probabilitas yaitu $0,000<$ 0,05 maka $\mathrm{H}_{\mathrm{a}}$ diterima dan $\mathrm{H}_{0}$ ditolak. Variabel $\mathrm{X}_{1}$ mempunyai t-hitung sebesar 5,859 dan t-tabel 1,985, maka t-hitung > t-tabel dapat disimpulkan bahwa variabel $\mathrm{X}_{2}$ secara parsial mempunyai pengaruh signifikan terhadap loyalitas pelanggan (Y).

Variabel komikasi $\left(\mathrm{X}_{3}\right)$, secara parsial mempunyai pengaruh signifikan terhadap loyalitas pelanggan (Y), Nilai sig lebih kecil dari nilai probabilitas yaitu $0,000<$ 0,05 maka $\mathrm{H}_{\mathrm{a}}$ diterima dan $\mathrm{H}_{0}$ ditolak. Variabel $\mathrm{X}_{1}$ mempunyai thitung sebesar 4,792 dan t-tabel 1,985, maka t-hitung > t-tabel dapat disimpulkan bahwa variabel $\mathrm{X}_{3}$ secara parsial mempunyai pengaruh signifikan terhadap loyalitas pelanggan (Y).

Variabel penanganan keluhan $\left(\mathrm{X}_{4}\right)$, secara parsial mempunyai pengaruh signifikan terhadap loyalitas pelanggan (Y), Nilai sig lebih kecil dari nilai probabilitas yaitu $0,005<$ 0,05 maka $\mathrm{H}_{\mathrm{a}}$ diterima dan $\mathrm{H}_{0}$ ditolak. Variabel $\mathrm{X}_{1}$ mempunyai thitung sebesar 2,870 dan t-tabel 1,985, maka t-hitung > t-tabel dapat disimpulkan bahwa variabel $\mathrm{X}_{1}$ secara parsial mempunyai pengaruh signifikan terhadap loyalitas pelanggan (Y).

2. Variabel kepercayaan, komitmen, komunikasi, dan penanganan keluhan secara simultan berpengaruh secara signifikan terhadap loyalitas pelanggan, nilai signifikan F sebesar $0,000<0,05$ dan $F_{\text {hitung }} 28,273>F_{\text {tabel }} 2,47$, maka $\mathrm{H}_{0}$ ditolak dan $\mathrm{H}_{\mathrm{a}}$ diterima sehingga variabel kepercayaan $\left(\mathrm{X}_{1}\right)$, komitmen $\left(\mathrm{X}_{2}\right)$, komunikasi $\left(\mathrm{X}_{3}\right)$, dan penanganan keluhan $\left(\mathrm{X}_{4}\right)$ secara bersama - sama berpengaruh signifikan terhadap loyalitas pelanggan pada Lyly Bakery Lamongan.

3. Di antara variabel kepercayaan $\left(\mathrm{X}_{1}\right)$, komitmen $\left(\mathrm{X}_{2}\right)$, komunikasi $\left(\mathrm{X}_{3}\right)$, dan penanganan keluhan $\left(\mathrm{X}_{4}\right)$, yang paling dominan 
mempengaruhi loyalitas pelanggan adalah variabel komitmen. Keseluruhan variabel bebas mempunyai nilai yang signifikan dengan arah positif. Dimana persamaan regresiY $=2,112+$ $0,135 X_{1}+0,195 X_{2}+0,186 X_{3}+$ $0,144 \mathrm{X}_{4}$, variabel komitmen yang mempunyai nilai yang paling tinggi sebesar 0,195 dengan demikian dapat ditarik kesimpulan bahwa variabel yang paling dominan memepengaruhi loyalitas pelanggan dalam penelitian ini adalah komitmen.

\section{Saran}

Beberapa saran yang dapat diajukan berkaitan dengan kesimpulan adalah sebagai berikut :

1. Bagi Perusahaan

Diharapkan kepada perusahaan dalam hal ini Lyly Bakery Lamongan yang diwakili oleh cabang-cabang resminya harus selalu melakukan riset terus menerus untuk mengetahui apakah kepercayaan $\left(\mathrm{X}_{1}\right)$, komitmen $\left(\mathrm{X}_{2}\right)$, komunikasi $\left(\mathrm{X}_{3}\right), \quad$ dan penanganan keluhan $\left(\mathrm{X}_{4}\right)$ mempengaruhi konsumen terhadap loyalitas pelanggan. Untuk itu, kepada Lyly Bakery Lamongan dapat mengambil sikap dalam dimensi reliationship markrting terhadap loyalitas pelanggan. Jadi, dari beberapa variabel dimensi reliationship markrting yang cukup dominan adalah variabel komitmen maka dari itu, pemberian komitmen, dengan banyaknya pesaing disarankan kepada perusahaan untuk mengamati kecenderungan dalam meberikan komitmen terhadap pelanggan tersebut.

Bila indikator ekonomi menunjukkan resesi, pemasar dapat mengambil langkah - langkah untuk merancang ulang, dan mengubah komitmen sesuai dengan situasi ekonomi target pasar yang telah ditentukan, agar konsumen dapat memiliki loyalitas dalam pembelian produk yang ditawarkan oleh perusahaan. Dan diharapkan kepada Lyly Bakery Lamongan lebih banyak memperhatikan dimensi reliationship markrting tersebut. Seperti melakukan inovasi serta pertimbangan dalam pemberian komitmen atas loyalitas pelanggan agar konsumen menjatuhkan pilihannya pada Lyly Bakery Lamongan tersebut.

2. Bagi Peneliti Selanjutnya

Diharapkan dapat memperkaya konsep atau teori yang mendukung perkembangan ilmu pengetahuan manajemen pemasaran, khususnya yang terkait dengan pengaruh dimensi relationship marketing terhadap loyalitas pelanggan dan variabel lain yang tidak diteliti suatu misal bauran pemasaran yang tidak dibahas dalam penelitian ini adalah orang, proses, dan lingkungan fisik yang mempengaruhi loyalitas pelanggan.

\section{DAFTAR PUSTAKA}

Alma, Buchari. 2013. Manajemen Pemasaran dan Pemasaran Jasa. Alvabeta, CV. Bandung.

Ashari, Purbayu Budi Santoso. 2010. Analisis statistic dengan microsoft exel dan SPSS. Yogyakarta.

Ellena, Frieda. 2011.Analisis Pengaruh Kepercayaan, Komitmen,

Komunikasi,dan Penanganan Keluhan Terhadap Loyalitas Nasabah (Studi Pada Nasabah PT. BRI (Persero) Tbk. Cabang Pemalang). Skripsi. Semarang: Fakultas Ekonomi UNDIP.

Sugiyono. 2014. Metode Penelitian Bisnis. (Pendekatan Kuantitatif, Kualitatif, Dan R\&D). Alvabeta, Bandung. 
Ferdinan. Augusty. 2014. Metode Penelitian Manajemen. Pedoman Penelitian Untuk Penulisan Skripsi, Tesis, dan Disertai Ilmu Manajemen. Badan Penerbit Universitas Diponegoro.

Ghozali, Imam. 2011. Aplikasi Analisis Multivariate Dengan Program SPSS.Semarang: BP Universitas Diponegoro.

2009. Ekonometrika Teori, Konsep dan Aplikasi Dengan SPSS17. Semarang: Badan Penerbit Universitas Diponegoro.

Harun, Harniza. 2011. Pengaruh Customer Relationship Marketing Dan Nilai Nasabah Terhadap Loyalitas Nasabah(Studi Kasus: Pada PT bankmuamalat Cabang Jambi). Jurnal Manajemen Pemasaran Modern. Vol. 3 No.1 Januari-Juni 2011.

Jushermi, Ari Asriandi. 2013. Pengaruh Relationship Marketing Terhadap Loyalitas Pengguna Kartu Kfc Music Hitter Pada Kfc Sudirman Pekanbaru. JURNAL EKONOMI Volume 21, Nomor 3 September 2013.

Keller, Kotler. 2009. Manajemen Pemasaran. Erlangga. Jakarta. Jl. H. Baping Raya No. 100 Cirasas.

Listyawati, Indri Hastuti. 2013. Implementasi Relationship Marketing Sebagai Strategi Mempertahankan Loyalitas Pelanggan. ISSN : 2252-5483. JBMA-Vol. I, No. 2, Februari 2013.

Murti, Herdina, Sasanti. 2013. Pengaruh dimensi relationship marketing terhadap loyalitas pelanggan (Studi Kasus pada Katering Prima Semarang).Skripsi. Semarang : Program pascasarjana Universitas Negeri Semarang.
Priyatno, Dwi. 2016. SPSS Handbook. MediaKom. Yogyakarta.

Purwono, Edi Kurniawan. 2010. Pengaruh Dimensi Relationship Marketing Terhadap Loyalitas Konsumen (Studi Pada Bengkel Ahass No.1267 Honggowongso). Skripsi. Surakarta. Fakultas EkonomiUniversitas Sebelas Maret.

Saputra, Murry Harmawan. 2010. Pengaruh Relationship Marketing Pada Loyalitas Mahasiswa Program Magister Sains Fakultas Ekonomika Dan Bisnis Universitas Gadjah Mada Yogyakarta.Ejournal.umpwr.ac.id /index.php/segmen/article/view/27 181 oleh MH Saputra - 2010.

Semuel, Hatane. 2012. Customer Relationship MarketingPengaruhnya Terhadap Kepercayaan dan Loyalitas Perbankan Nasional. Jurnal Manajemen Pemasaran, Vol. 7, No. 1, April 2012.

Sutopo. 2011. Pengaruh implementasi relationship marketing Terhadap loyalitas konsumen pada produk oli Pelumas pt pertamina (persero) enduro 4t Kumbokarno borneo. Jurnal Ekonomi - April 2011 Vol. 1 Nomor 1.

Supriyanto, Ernawati. 2010. Pemasaran Industtri Jasa Kesehatan. ANDI OFFSET, Cv. Yogyakarta.

Tjiptono, Fandy. 2015. Pemasaran. Penerbit ANDI. Yogyakarta.

Umar, Husein. 2009. Metode Riset Bisnis. Jakarta: PT.Gramedia Pustaka Utama. 